\title{
ADDRESSING RESEARCH DESIGN PROBLEM IN MIXED METHODS RESEARCH
}

\author{
Hamed ALAVI \\ Tallinn University of Technology \\ Patrycja HĄBEK \\ Silesian University of Technology
}

\begin{abstract}
:
Alongside other disciplines in social sciences, management researchers use mixed methods research more and more in conduct of their scientific investigations. Mixed methods approach can also be used in the field of production engineering. In comparison with traditional quantitative and qualitative research methods, reasons behind increasing popularity of mixed research method in management science can be traced in different factors. First of all, any particular discipline in management can be theoretically related to it. Second is that concurrent approach of mixed research method to inductive and deductive research logic provides researchers with opportunity to generate theory and test hypothesis in one study simultaneously. In addition, it provides a better justification for chosen method of investigation and higher validity for obtained answers to research questions. Despite increasing popularity of mixed research methods among management scholars, there is still need for a comprehensive approach to research design typology and process in mixed research method from the perspective of management science. The authors in this paper try to explain fundamental principles of mixed research method, its typology and different steps in its design process.
\end{abstract}

Key words: research design, quantitative research methods, qualitative research methods, mixed research methods

\section{INTRODUCTION}

The term research design has been interchangeably used with research method [19]. Despite the fact that main research methods are known as qualitative, quantitative and mixed methods, research design might have different implications in different situations. For example, in one research it may refer to the whole research process from first steps in defining the research problem to research questions, literature review, methods and conclusions, however, in another research, it might be limited only to methodology including data collection and analysis. It is important to identify research design as it conveys message about key features of research and they can be different in qualitative, quantitative and mixed methods.

With its emphasis on numerical data, quantitative method was the dominant method for research in the management science during last century, however, qualitative research started popularity in the second half of twentieth century by focusing on information collection via communication and interpretive analysis of data [21]. Despite the fact that mixed research method can be traced to multi-trait, multi-method approach introduced by Campbell and Fisk in 1959 [36]. It started to gain popularity as an alternative to main two paradigms from early years of 1990 [35]. Mixed research method is also known as the third path [14], the methodological movement [37] and the third research paradigm [23]. Capability to integrate thematic and statistical data is considered as the main strength point of mixed research method and reason behind its increasing popularity among management scholars [38].
Current research presents mixed research method known as the third research paradigm and its application to research design in management science as well as in production engineering. In doing so, paper will study different definitions of mixed methods research, clarifying which research questions can be answered by application of mixed method, different steps in designing a mixed method research and finally different types of mixed research method applicable to management research .

\section{LITERATURE REVIEW}

Mixed research method has been defined by different scholars in different ways. The first definition of mixed method is provided by Greene, Caracelli, and Graham [15] as: "In this study, we defined mixed-method designs as those that include at least one quantitative method (designed to collect numbers) and one qualitative method (designed to collect words), where neither type of method is inherently linked to any particular inquiry paradigm".

Latter definition by Tashakori and Tiddle moved from mixing two methods to mixing all steps of research process: "qualitative and quantitative approaches in the methodology of a study" [38]. Other renowned definitions of mixed method can be mentioned as: "mixed methods research is the type of research in which a researcher or team of researchers combines elements of qualitative and quantitative research approaches (e.g., use of qualitative and quantitative viewpoints, data collection, analysis, inference techniques) for the purposes of breadth and depth of understanding and corroboration" [22]. "Mixed methods rese- 
arch is defined as research in which the investigator collects and analyses data, integrates the findings, and draws inferences using both qualitative and quantitative approaches and methods in a single study or a program of inquiry" [39] and ". . . that actively invites us to participate in dialogue about multiple ways of seeing and hearing, multiple ways of making sense of the social world, and multiple standpoints on what is important and to be valued and cherished" [16].

Mixed method is advocated by management scholars due to two main advantages: first, it has the theoretical capacity to be used in different scientific discipline including: human resources, strategic management, production engineering, sociology, education, organizational behaviour and psychology as well as healthcare. Second it can ensure the reliability and validity of research outcomes due to variable research questions which it can answer [4, 6, 13, 33].

Many management scholars have advocated application of mixed research method in management research due to its particular characteristics. Jogulu and Pansiri [21] discussed the possibility for simultaneous use of inductive and deductive research logic by applying mixed research method. According to them, such opportunity will provide researchers to generate theory and examine the hypothesis in one study. Jogulu and Pansiri also argue that due to subjective nature of social experiences (including management research), it is recommended to have more in depth knowledge from interpretations of experiences which are relevant to the social phenomenon rather than sole reliance on validity of data collected by application of quantitative methods. Therefore, using interview and focus group techniques in addition to survey questioners will provide consistency between experience and subjective views to a social phenomenon and statistical data collected in quantitative method [21].

Jack and Raturi studied capability of the mixed research method in combining statistics and thematic data in process of data analysis and concluded that such combination will result in strengthening research findings through triangulation [20]. This is considered as a complementary strength without any overlapping weakness [21] where application of mixed research method will add value of soft-core experiences collected via interview to hard data generated by questioners [32].

According to Caracelli and Greene [17], there are three main applications for mixed research method: "(1) testing the match of findings obtained from different measuring instruments, (2) clarifying and building on the results of one method with another method, and (3) demonstrating how the results from one method can impact subsequent methods or inferences drawn from the results". Also Greene, Caracelli and Graham [15] define five reasons for increasing popularity of mixed research methods:

- first is triangulation which as discussed before will increase the consistency in finding of study,

- second is complementarity which is resulted in application of quantitative and qualitative methods to describe overlapping but different phenomenon in one study,

- third is development which refers on influence of one applied method on other methods and steps of a single study,

- fourth reason is initiation which goes back to challenge imposed by results achieved from application of one method on results obtained from application of other method. Such challenge can result in defining new directions for the study,

- finally, fifth reason for using mixed method is expansion which refers to clarification of study's result and add value to findings by application of both quantitative and qualitative methods.

\section{RESEARCH METHOD}

Current paper presents study on theory of research methods and on the basis of extensive literature review in the field of research methodology and research design with focus on mixed research method. On the basis of electronic research in academic databases, a comparative study has taken place among exiting literature on application of mixed research method in management science to define different styles of mixed method research design and its relevant attributes in management research.

\section{DIFFERENT TYPES OF MIXED METHOD DESIGN}

Scholars from different areas of science have contributed in identification and development of mixed research method (see Fig. 1) [11, 31, 37, 38]. However, mixed research method has firm roots in evolution literature and majority of existing frameworks on mixed method studies are referenced to work of evolution scholars [15, 17, 11, 23, 24, $30,27,29,37]$. Despite the fact that identified frameworks for mixed method design are significantly different from each other, but mixed method managed is recognized as strong and precise research tool in field of management research. However, it should not be forgotten that neither of those frameworks have been dominantly endorsed by scholars [19].

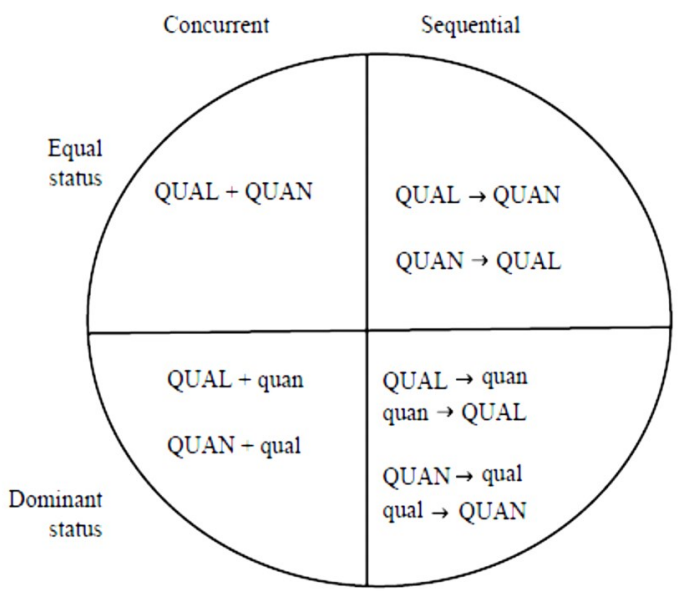

Notes: "Qual" stands for qualitative; "quan" stands for quantitative;
"- " stands for concurrent; " $\rightarrow$ " stands for sequential; capital
letters - "QUAL" and "QUAN" denote high priority or weight;
lower case letters - "qual" and "quan" denote lower priority or
weight

Fig. 1 Mixed Methods Design Matrix

Source: [21].

For the purpose of this paper, framework of Creswell [11] will be used in order to explain different design models in mixed research method. Creswell describes a guide for construction of mixed method features by introducing six models for design and refers to them as strategies of inquiry. Criteria for distinguishing strategies of inquiry from each other include: sequential or concurrent collection of quantitative and qualitative data, whether one type of data has been used as reference for other one or they are given same weight in the study, where and when does the mixing 
of data appear, which theoretical paradigm (positivism, constructivism, etc.) is dominant throughout the research [19]. The six models of approaches to mixed method design are discussed below.

Sequential Explanatory Design is the first approach to mixed method described by Creswell. Theoretical basis might or might not be influential in this approach as focus will be on providing explanation and interpreting relations among variables. Therefore, quantitative data will be collected first and it will complemented, followed and enhanced by qualitative data. As a result, quantitative and qualitative data will be collected and interpreted separately while results will be integrated after interpretation of findings [11]. This approach gives more weight to quantitative rather than qualitative components. Strength of sequential exploratory method can be considered in separate phases of design, data collection and interpretation for each group of qualitative and quantitative data. However, weak points of this method should be searched in time and cost of separate data collection phases and demand for expertise in integration of results achieved from interpretation of quantitative and qualitative data.

According to Morgan [26], sequential explanatory design can be considered as the most frequently used among mixed method design approaches.

Sequential Exploratory Design is the second design approach in mixed method research. In contrast with former approach, during the process of sequential exploratory design, quantitative data will be used as a complementary factor in interpretation of findings from qualitative data. This form of design will apply to studies which follow the goal of enhancing generalization with or without influence of theoretical perspectives. According to Creswell [11] instrument construction is a popular practice in this approach where an instrument like survey or test will be used as pilot for a small population and collecting important qualitative data on the basis of their experience with research problem. Later, follow up modifications and corrections on instrument will lead to collection of quantitative data which enhance and complement results of pilot study. Sequential exploratory design has similar weak points and strengths as previous approach.

Sequential Transformative Design is third approach to mixed method research. In this method either type of data can be collected first. While theoretical perspective plays a significant role in conduct of the research, used methods should reflect theoretical perspective properly. After separate analysis of qualitative and quantitative data, integration of outcomes will take place during the interpretation phase. This particular design approach will be considered when it is necessary to ensure representation of diverse range of participants [11]. Strengths and weaknesses of sequential transformative design are similar and comparative to sequential exploratory and explanatory design approaches [19].

Concurrent Triangulation Design is the fourth mixed method design approach discussed by Creswell. It is mostly applicable to conditions where the main idea behind the study is corroborating, cross-validating or confirming of the findings. Despite the fact that one type of data can have more important role in this design approach, qualitative and quantitative data in general have similar weight during the integration phase and they are collected simultaneously in order to cover each other's weaknesses. Different types of data are collected and analysed separately while integration of findings will take place during interpretation phase [11]. Strengths of concurrent triangulation design can be summarized as reducing the time of data collection and weakness can be mentioned as problems for correct application of quantitative and qualitative data collection process at the same time plus finding a justification for existing discrepancies in quantitative and qualitative data [19].

Concurrent Nested Design is the fifth design approach explained by Creswell. In this design approach, qualitative and quantitative data are collected concurrently and analysis of types of data will take place together [11]. Either type of data can have more significant weight as the other type of data will be used in embedded format [19]. One of the main occasions for application of concurrent nested design is multilevel structural studies where different levels or unites of a single organization will be studies at the same time [37]. Multiple embedded perspectives in collected data and shorter period of data collection are main advantages of concurrent nested design while weakness of using this approach can be considered as necessity expertise in process of combining qualitative and quantitative data and existing discrepancies in finding from analysis of different types of data [19].

Concurrent Transformative Design. Similar to sequential transformative design it is guided by clear and defined theoretical perspective. In this design approach, quantitative and qualitative data are collected at the same time and mixed during analysis phase. However, they might have equal or non-equal weight in the study [11]. Similar to other concurrent design approaches, shorter data collection time can be considered as the main strength of concurrent transformative design approach whereas, necessity to transform data in order to mix it during the analysis process and resistance of conflicting outcomes from analysis of quantitative and qualitative data can considered as main weaknesses of this design approach [19].

\section{DISCUSSION}

Providing justification to use a research method during the process of study is one of the fundamental steps in choosing the method by researcher in all fields of science as well as management science. In doing so, researcher should prove that research design is capable of providing best answers to research questions. However, no single method can provide best answer to all research questions. For example, quantitative research method is suitable when researcher aims at exploring a problem, provide an in depth study and explain multiple perspectives. On the other hand, qualitative research method can provide best answer when researcher is trying to define relationship among variables or explore reasons behind better performance of one group in comparison with others. Therefore, it seems logical to find out that which types of research question can be answered by the mixed method before taking further steps in defining different types of mixed method research design and their application in management science.

Creswell and Clark [10] define six types of research question which can be suitably answered by mixed method. First group is type of questions which need more than one source of data. This might happen due to different reasons like inadequacy of collected data by one method of research or lack of researcher's expertise in exploiting a research method at full scale. Second group are research questions in which the initial result is in need of further expla- 
nation. This is common problem when result of quantitative research only provides general relations among variables, but a further understanding from statistical tests are needed. In such occasions, mixed method can be a preferable for research design as it can fill the gap in meaningfulness of results. Third are questions which need further enhancement of study by using second method. It is very popular in management research to face with occasions that a second method is applied in research design to enhance the understanding from some phases of research. This can happen by adding qualitative data to quantitative design or the other way around. However, "embedding qualitative method in quantitative study is more popular" [8]. Fourth is the group of questions which theoretical framework provides situation in need of using mixed method for collecting data by simultaneous application of quantitative and qualitative research design. Data can be collected simultaneously, or in a sequential form by using one type of data as a basis for other one. Fifth group are questions which are in need of providing better understanding from objectives of research via using multiple research phases. This applies to long span projects when research will take many years and it includes many components such as organizational evaluation studies. In such projects, quantitative and qualitative data can be collected simultaneously or sequentially. Such researches are also famous as multiproject or multi-phase mixed method studies and they involve different teams of researchers who collaborate with each other during multiple phases of study [8].

Finally, sometimes guiding theories of the study, variables for being measures and questions to be asked in the research are not clear for researcher. Such situation is very popular when the research topic is something new or subjects of research are not available. Mixed method design can be very useful in such condition as application of qualitative questions will provide enough insights for researcher which theories to use, which questions to ask and which variables to measure. Later, application of qualitative method can provide a generalized picture from what has been studied [8].

\section{CHALLENGES FOR APPLICATION OF MIXED METHOD DE- SIGN IN MANAGEMENT RESEARCH}

Despite the fact that mixed method research provides a flexible research designs which match the need for rigours examination of research problems in different management driplines, it is necessary to keep in mind significant challenges for its application in process of management research $[5,9,24,36]$.

A very important challenge for application of mixed method research is achieving a reconciliation in paradigm war. There is no doubt that still many researchers do not agree on possibility to use quantitative and qualitative methods at the same time [34] while mixed method research literature consider the such disagreements resolved by taking a pragmatic stance $[7,10,18,37]$. Next challenge is providing a commonly accepted definition from mixed method research including components (research question, data collection, design, data analysis and interpretation), time and method for mixing components $[3,5,23,27,37$, 40]. In addition to above mentioned challenges, we also need to consider the necessity for access to sufficient time and resources to collected and analyse two different types of data as well as existence of relevant skills for application of mixed method research method.

\section{CONCLUSIONS}

The main objective of current paper is addressing the problem of research design in mixed research method which is considered by Teddlie and Tashakkori [37] as the third methodological movement. In achieving its objective, research tried to explain fundamental principles of mixed method research, analyse its different types with reference to Creswell Framework [11], define suitable research questions which can be answered by application of mixed method design and finally point at existing challenges on the way for it application.

There is no doubt that quantitative research design is still the most popular research method in management science which is followed by qualitative design [25]. Application of mixed research method has relative short life span in management research and its application is much more limited in comparison with either of qualitative and quantitative methods $[1,2,12]$. However, due to its flexibility in offering different research designs, mixed method research can offer researchers more creative design, data gathering and analysis in almost all areas of management discipline as well as in production engineering. Despite the fact that popularity of mixed method research is growing among management researchers still many criticisms exist on the way of its full scale application which should be answered by its proponents.

\section{REFERENCES}

[1] L.M. Anderson and T.S. Bateman. „Individual environmental initiative: championing natural environmental issues in US business organizations", in Academy of Management Journal, vol. 43(4), August 2000, pp. 548 -70 .

[2] P. Bansal and K. Roth. „Why companies go green: a model of ecological responsiveness", in Academy of Management Journal, vol. 43(4), August 2000, pp. 717 $-36$.

[3] P. Bazeley. "Mixed methods data analysis”, in Mixed methods research for nursing and the health sciences, E. Halcomb and S. Andrew, London: Wiley-Blackwell, 2009, pp. 84-118.

[4] R.S. Brause. Writing Your Doctoral Dissertation: Invisible Rules for Success, London: Falmer Press, 2000.

[5] A. Bryman. „Barriers to integrating quantitative and qualitative research", in Journal of Mixed Methods Research, vol. 1(1), January 2007, pp. 8-22.

[6] R.L. Calabrese. The Elements of an Effective Dissertation and Thesis: A Step-by-step Guide to Getting It Right the First Time, Lanham (MD): Rowman \& Littlefield, 2006.

[7] J.W. Carey. „Linking qualitative and quantitative methods: Integrating cultural factors into public health", in Qualitative Health Research, vol. 3(3), August 1993, pp. 298-318.

[8] J.W. Creswell et al. Best practices for mixed methods research in the health sciences, in Bethesda (MD): National Institutes of Health, 2011, pp. 2094-2103.

[9] J.W. Creswell. Research design: Qualitative, quantitative, and mixed methods approaches, Thousand Oaks (CA): SAGE Publications Inc., 2009.

[10] J.W. Creswell and V.L. Plano Clark. Designing and conducting mixed methods research, Thousand Oaks (CA): SAGE Publications Inc., 2007.

[11] J.W. Creswell et al. „Advanced mixed methods research designs", in Sage Handbook of Mixed Methods 
in Social \& Behavioral Research, A. Tahakkori and C. Teddlie, Thousand Oaks (CA): SAGE Publications Inc., 2003, pp. 209-240.

[12] C.P. Egri and S. Herman. „Leadership in the North American environmental sector: values, leadership styles, and contexts of environmental leaders and their organizations", in Academy of Management Journal, vol. 43(4), August 2000, pp. 571-604.

[13] J.A. Finn. Getting a PhD: An Action Plan to Help Manage Your Research, Your Supervisor and Your Project, New York (NY): Routledge, 2005.

[14] S. Gorard and C. Taylor. Combining Methods in Educational and Social Research, Buckingham: Open University Press, 2004.

[15] J.C. Greene, V.J. Caracelli and W.F. Graham. „Toward a conceptual framework for mixed method evaluation design", in Educational Evaluation and Policy Analysis, vol. 11(3), September 1989, pp. 255-274.

[16] J.C. Greene. Mixed methods in social inquiry, San Francisco (CA): Jossey-Bass, 2007.

[17] J.C. Greene and V.J. Caracelli. „Defining and describing the paradigm issue in mixed-method evaluation", in New Directions for Evaluation, vol. 1997(74), March 1997, pp. 5-17.

[18] J.E. Haase and S.T. Myers. „Reconciling paradigm assumptions of qualitative and quantitative research", in Western Journal of Nursing Research, vol. 10(2), April 1988, pp. 128-137.

[19] M.R. Harwell. "Research design in qualitative/ quantitative/mixed methods", in The Sage handbook for research in education: Pursuing Ideas as the Keystone of Exemplary Inquiry, C.F. Conrad and R.C. Serlin, Los Angeles (CA): SAGE Publications Inc., 2011, pp. 147-163.

[20] E.P. Jack and A.S. Raturi. „Lessons learned from methodological triangulation in management research", in Management Research New, vol. 29(6), 2006, pp. 345357.

[21] U.D. Jogulu and J. Pansiri. „Mixed methods: A research design for management doctoral dissertations", in Management Research Review, vol. 34(6), 2011, pp. 687-701.

[22] R.B. Johnson, A.J. Onwuegbuzie and L.A. Turner. "Toward a definition of mixed methods research", in Journal of Mixed Methods Research, vol. 1(2), April 2007, pp. 112-133.

[23] R.B. Johnson and A.J. Onwuegbuzie. „Mixed methods research: A research paradigm whose time has come", in Educational Researcher, vol. 33(7), October 2004, pp. 14-26.

[24] F. Lawrenz and D. Huffman. „The archipelago approach to mixed method evaluation", in American

\footnotetext{
Hamed Alavi

Tallinn University of Technology

Akadeemia Tee 3, Tallinn 12618, ESTONIA

e-mail: hamed.alavi@ttu.ee

dr inż. Patrycja Hąbek

Silesian University of Technology,

Faculty of Organization and Management

Institute of Production Engineering

ul. Roosevelta 26, 41-800 Zabrze, POLAND

e-mail: Patrycja.Habek@polsl.pl
}

Journal of Evaluation, vol. 23(3), September 2002, pp. 331-338.

[25] M.E. Mendenhall, D. Beaty and G.R. Oddou. „Where have all the theorists gone? An archival review of the international management literature", in International Journal of Management, vol. 10(2), 1993, pp. 146-153.

[26] D.L. Morgan. „Practical strategies for combining qualitative and quantitative methods: Applications to health research", in Qualitative Health Research, vol. 8(3), May 1998, pp. 362-376.

[27] J.M. Morse. „Simultaneous and sequential qualitative mixed method designs", in Qualitative Inquiry, vol. 16(6), July 2010, pp. 483-491.

[28] J.M. Morse. „Procedures and practice of mixed method design: Maintaining control, rigor, and complexity", in Sage Handbook of Mixed Methods in Social \& Behavioral Research, A. Tahakkori and C. Teddlie, Thousand Oaks (CA): SAGE Publications Inc., 2010, pp. 339353.

[29] I. Newman et al. „A typology of research purposes and its relationship to mixed methods", in Sage Handbook of Mixed Methods in Social \& Behavioral Research, A. Tahakkori and C. Teddlie, Thousand Oaks (CA): SAGE Publications Inc., 2003, pp. 167-208.

[30] A.J. Onwuegbuzie et al. "Conducting mixed analyses: A general typology", in International Journal of Multiple Research Approaches, vol. 1(1), October 2007, pp. 4-17.

[31] J. Pansiri. „Pragmatism: A methodological approach to researching strategic alliances in tourism", in Tourism and Hospitality Planning \& Development, vol. 2(3), 2005, pp. 191-206.

[32] A. Parkhe. „'Messy' research, methodological predispositions, and theory development in international joint ventures", in Academy of Management Review, vol. 18(2), April 1993, pp. 227-268.

[33] E.M. Phillips and D.S. Pugh. How to Get a PhD: A Handbook for Students and Their Supervisors, 4th ed., Maidenhead: Open University Press, 2005.

[34] M. Sandelowski. „Tables or tableaux? The challenges of writing and reading mixed methods studies", in Sage Handbook of Mixed Methods in Social \& Behavioral Research, A. Tahakkori and C. Teddlie, Thousand Oaks (CA): SAGE Publications Inc., 2003, pp. 321-350.

[35] A. Tashakkori. "Are we there yet? The state of the mixed methods community", in Journal of Mixed Methods Research, vol. 3(4), October 2009, pp. 287 291.

[36] A Tashakkori and C. Teddlie. Foundations of mixed methods research: Integrating quantitative and qualitative approaches in the social and behavioral sciences, Thousand Oaks (CA): SAGE Publications Inc., 2009.

[37] A. Tashakkori and C. Teddlie (Eds.). Handbook of Mixed Method in the Social and Behavioral Research, Thousand Oaks (CA): SAGE Publications Inc., 2003.

[38] A. Tashakkori and C. Teddlie. Mixed Methodology: Combining Qualitative and Quantitative Approaches, Thousand Oaks (CA): SAGE Publications Inc., 1998.

[39] A. Tashakkori and J.W. Creswell. „Editorial: The new era of mixed methods", in Journal of Mixed Methods Research, vol. 1(1), January 2007, pp. 3-7.

[40] J. Wheeldon. „Mapping mixed methods research: Methods, measures, and meaning", in Journal of Mixed Methods Research, vol. 4(2), April 2010, pp. 87102. 